\section{Death of a Middle-Aged Man after Long Term Abuse of a Combination Anticholinergic, Beta Blockers and Narcotic Drugs: A Suspected Münchau- sen Syndrome Case Report}

\author{
Madae'en $\mathrm{S}^{1}$, Bostamy $\mathrm{B}^{2}$, Jaber $\mathrm{D}^{1}$ and Wazaify $\mathrm{M}^{1 *}$ \\ ${ }^{1}$ Department of Biopharmaceutics and Clinical Pharmacy, University of \\ Jordan, Amman, Jordan \\ ${ }^{2}$ Department of Cardiovascular Diseases, Jordan University Hospital, \\ Jordan
}

\begin{abstract}
\section{Background}

Münchausen syndrome is a mental illness, in which a person repeatedly acts as if he or she has a physical, emotional or cognitive disorder when, in truth, he or she has caused the symptoms. Although it has been described in the medical literature as "seeking attention" tool, Münchausen syndrome in this case report is also suspected to be the cause for drug addiction.

\section{Case descriptions}

This was a 45-year-old male patient with multiple medical complains over the years, most of his complaints could not be explained on clinical or organic basis. We believe that his main goal was to justify his drug seeking behavior and to obtain different forms of secondary gains and social security support. The patient was secretly abusing a cocktail of anticholinergic and narcotic drugs which we believe eventually led to his death. He claimed to have chronic headaches and back pain and caused self harm, such as intentionally opening the surgical wound over his pace-maker, in order to obtain narcotic analgesics. Moreover, he was secretly taking a beta-blocker without any prescription to deliberately induce bradycardia so that he could obtain atropine from the hospital.

Conclusion

This case report is important because missing the diagnosis of Münchausen's syndrome possibly resulted in the inappropriate course of action in his treatment. There could have been some use of
\end{abstract}

*Corresponding author: Wazaify M, Department of Biopharmaceutics and Clinical Pharmacy, University of Jordan, Amman 11942, Jordan, Tel: +96265355000; Fax: +96265300250; E-mail: M.Wazaify@ju.edu.jo

Citation: Madae'en S, Bostamy B, Jaber D, Wazaify M (2015) Death of a Middle-Aged Man after Long Term Abuse of a Combination Anticholinergic, Beta Blockers and Narcotic Drugs: A Suspected Münchausen Syndrome Case Report. J Addict Addictv Disord 2: 007

Received: March 28, 2015; Accepted: July 10, 2015; Published: July 29, 2015

Copyright: (c) 2015 Mbaebie N and Veeranna V, This is an open-access article distributed under the terms of the Creative Commons Attribution License, which permits unrestricted use, distribution, and reproduction in any medium, provided the original author and source are credited. psychoanalysis and cognitive behavioural therapy or an addition of a selective serotonin reuptake inhibitor. Moreover, this case reports the abuse of beta blockers for the sake of causing bradycardia and seeking anticholinergic drugs. It is suggested that clinicians consider the specific motivation for drug abuse in all cases of factitious $d$ isorders such as Münchausen's syndrome, and avoid any assumption that it has been carried out for the purpose of controlling genuine symptoms. Involvement of psychiatrists is strongly recommended.

\section{Case Presentation}

The patient is a truck driver that has 7 siblings.

The history goes back to when the patient was 33 years old and presented to the cardiovascular department complaining of fainting episodes, described as syncope and sometimes convulsions. He was noted to have bradycardia and occasional $2^{\text {nd }}$ degree Artioventricular node (AV) block. A pacemaker was placed for him but he continued to have the same spells.

The patient was seen by neurologists, diagnosed with epilepsy of generalized tonic-clonic seizure and started on anticonvulsant therapy with more than one drug and increasing doses (clonazepam $4 \mathrm{mg} \mathrm{x} 3$ and levitricetam 500mg x 3), but he continued to have his fainting spells.

Investigations that involved Computed Tomography (CT) scan, Electroencephalography (EEG) scan and Magnetic Resonance Imaging (MRI) studies of the head were normal.

When the patient was 41 years old he was admitted to the hospital repeatedly with Gastrointestinal (GI) symptoms and occasional hematoemesis. Endoscopy showed peptic reflux esophagitis and he admitted to ingesting detergents and caustic chemicals in a suicide attempt.

During his repeated hospital stay, he used to complain chronically of headaches and insomnia, requesting sedatives and analgesics; tramadol and codeine from the doctors and nurses. He also started to complain of back pain, again requiring regular large doses of analgesics including the aforementioned narcotics. Again, CT scan and MRI of the back were normal.

At the age of 43 , he started to have an "unexplained" bradycardia and it was then felt that the pacemaker maybe was coming to an end of its life as he was getting more of his "fainting episodes". The pace maker was changed, removed and had to be reinserted a few months later. After three months, the pacemaker wound site became infected (it seemed that the patient reopened the wound over the pacemaker himself), requiring prolonged intravenous antibiotic therapy. Thus, the pacemaker was removed because of infection. His baseline rhythm was sinus bradycardia, and it was discovered by the resident doctor that the patient was secretly taking beta blockers (bisoprolol). The resident noticed it in his drawer when asking him to see his medications and asked him about it and he said it was prescribed for him. So, to maintain his slow heart rate and retain the medical attention the patient was requesting atropine frequently from the nursing staff to "improve" his heart rhythm. Then, the author Saba Madaeen (MS) discovered by accident that the patient was also getting Artane (trihexphenidyl) secretly from a friend over the phone. 
The patient was seen by psychiatrists on many occasions and was labeled as having personality disorder, depression, self-harming attitudes and occasionally hysterical behavior. The patient tried to commit suicide twice, once by methanol and the other by a glue overdose (as reported in his medical file).

After the author Saba Madae'en (MS) had discovered the medical abuse case, she consulted the responsible physician and confronted the patient with his inappropriate use of drugs. The patient continued in his denial. The researcher found in the patient's medical record a written request of help from the patient's wife to the patient's psychiatrist; she stated that the patient chronically left home for days and she did not know where he had been, as well as describing him as being abusive in their relationship. She added that "he doesn't show any interest in asking about his kids", that they don't get money from him and that they do not have enough food to eat. The psychiatrist said that this is "a hard case to deal with as the patient cannot be trusted and is not cooperative".

During that whole period of hospitalization, the patient was maintained regularly on: pethidine $50 \mathrm{mg}$ prn, codeine $60 \mathrm{mg}$ $\mathrm{x} 3$, antihistamines such as chlorphenramine, and different anticonvulsants levitricetam 500mg x 3 and clonazepam $4 \mathrm{mg}$ x 3 .

After a year and a half from the previous hospitalization, the patient was admitted to the Emergency Room (ER) with loss of consciousness. The patient received Cardiopulmonary Resuscitation (CPR), atropine and adrenaline immediately upon arrival as his Heart Rate (HR) was $25 \mathrm{bpm}$, Electrocardiogram (ECG) showed f Mobitz II $2^{\text {nd }}$ degree AV block. The next day, the patient had a HR of $45 \mathrm{bpm}$ and was given atropine $2 \mathrm{mg} I \mathrm{~V}$, his HR rose to $60 \mathrm{bpm}$. One month later, the patient had a syncope attack with HR of $35 \mathrm{bpm}$. The patient complained of abdominal pain and was given hyoscyamine $10 \mathrm{mg}$ $\mathrm{x} 3$. He also complained of constipation and was asked to stop tramadol but he refused. The patient was also given chlorpheniramine as he complained of itching. The patient was discharged and counseled about addiction of anticholinergics and narcotics.

The authors Saba Madae'en and Wazaify Mayyada read about the death of the patient in the newspaper at the age of 45 . During his stay he had no visitors and it was not possible to contact any real next of kin in order to get more information. The telephone numbers he gave were out of service.

\section{Discussion}

Although the patient was not diagnosed by the psychiatrists to have Münchausen syndrome, the authors Saba Madaeen and Wazaify Mayyada believe that our case is a clear one [1,2]. It was obvious that the goal of this patient's illness was to achieve self-satisfaction through different drug combinations and to retain his social security support by claiming illness and being in hospital most of the time. What we may try to present in this case is the use of atropine in combination with other drugs of abuse, where it may have additive effect and thus be abused $[3,4]$.

Münchausen syndrome is a psychiatric factitious disorder wherein those affected feign disease, illness, or psychological trauma to draw attention, sympathy, or reassurance to themselves. It is also sometimes known as hospital addiction syndrome, thick chart syndrome, or hospital hopper syndrome. True Münchausen syndrome fits within the subclass of factitious disorder with predominantly physical signs and symptoms, but patients also have a history of recurrent hospitalization, travelling, and dramatic, untrue, and extremely improbable tales of their past experiences [5].

Our patient displayed signs of Münchausen syndrome through drug seeking behavior and obtaining different forms of secondary gains and social security support. He persistently infected his wound to obtain surgical treatment, which is the most common case of Münchausen symptoms this may have added to his drug seeking behavior $[5,6]$.

Various approaches to the diagnosis of Münchausen syndrome have been described in the literature. O'Flynn et al., describe the following eight principal features: "pathological lying with the presentation of the history in a dramatic, vague and inconsistent manner; evidence of prior treatments; medical sophistication; disruptive hospitalisation; symptoms that shift from one organ system to another; tolerance of painful and invasive procedures without complaint; demands for analgesic medication; and either the absence, or collusion, of visitors" [7]. There is evidence of at least six of these features in our case.

The patient received a cocktail of narcotic, antiadrenergic (beta-blocker) and anticholinergic drugs (atropine, trihexphenidyl and hyoscyamine). This case reports for the abuse of beta blockers for the sake of causing bradycardia and seeking anticholinergic drugs. There have been several reports linking anticholinergics with psychosis [6,8-14]. It may be that patients with borderline personalities or affective disorders are particularly at risk of psychosis $[11,12]$. Opiates and alcohol may have additive effects with artane $[13,14]$ and so the potential for abuse exists. Moreover, the combination may cause what is called (anti-cholinergic syndrome with narcotics, antihistamines, inhibiting acetylcholine at muscarinic receptors (inhibiting parasympathetic nervous system, relaxing smooth muscles, causing hallucination, loss of memory and nervousness [15-17].

Dilsaver reported that the simultaneous administration of sub-threshold doses of atropine and amphetamine produced marked increases in non-rewarded responses [11]. Furthermore, the frequency of non-rewarded responses increased with the dose of either drug. This means that the effect of administering atropine was similar to that of increasing the dose of amphetamine [12].

The patient was obtaining trihexyphenidyl form secret sources. This drug in Jordan is classified as Schedule III, which means the drugs which may be sold by a pharmacist on a non prescription basis and which must be retained within the professional service area of the pharmacy where there is no public access and no opportunity for patient self-selection [18]. However, patients can get such medications by different illegal methods. The history initially taken from patients may not reveal the fact or the extent of drug usage, and routine screening for drugs may be negative. In our case the authors Saba Madae'en and Wazaify Mayyada noticed the drug abuse but the first year medical resident was instrumental in noticing the beta-blocker in the patient's possession while the patient denied using any medication. This helped in clarifying the case. The clinical presentation showed striking psychotic symptoms, including Münchausen's. The abuse of beta blockers maintained this patient's slow heart rate which secured his medical supply of the anticholinergic atropine.

\section{Conclusion}

The diagnosis suspected for our patient, i.e., Münchausen's syndrome presenting as beta blocker drug abuse in order to gain 
anticholinergic drugs of abuse rather than only seeking medical attention may represent a new variant of the syndrome. In light of this, clinicians should consider a range of specific motivations for the behaviour in all cases of clinically and organically unexplained illness, including the possibility of a factitious disorder such as Münchausen's syndrome. Involvement of psychiatrists is strongly recommended. Other cases of Münchausen's syndrome may present which could be identified and addressed more effectively if this approach were taken.

\section{Competing Interests}

The authors declare that they have no competing interests.

\section{Authors' Contributions}

Saba Madaeen and Wazaify Mayyada wrote the initial case report and commented on drafts of the paper. Jaber D carried out the literature search, contributed to the introduction and commented on drafts of the paper. Saba Madae'en carried out the detailed literature search on Münchausen's syndrome and primarily wrote the discussion section of the paper. Bostamy B was the cardiologist responsible for the case, and edited drafts to produce the final version.

\section{Consent}

Because the patient, in this case died before the authors decided to publish it as a case report, it was not possible to obtain written informed consent from him. We believe this case report contains a worthwhile clinical lesson which could not be as effectively made in any other way.

\section{References}

1. Bools C, Neale B, Meadow R (1994) Munchausen syndrome by proxy: a study of psychopathology. Child Abuse Negl 18: 773-788.

2. Trejo-Hernández J, Loredo-Abdalá A, Orozco-Garibay J (2011) Munchausen syndrome by proxy in Mexican children: medical, social, psychological and legal aspects. Rev Invest Clin 63: 253-262.

3. Skulska A, Kala M (2007) Consequences of Medical and Non-Medical Use of Atropine and Fentanyl Analogues. Problems of Forensic Sciences 71: 303312
4. Ridder WP, Klimek M, Rupreht J (2005) [Physostigmine for the immediate treatment of a patient with the central anticholinergic syndrome induced by cocaine cut with atropine]. Ned Tijdschr Geneeskd 149: 1701-1703.

5. Kay J, Tasman A (2006) Essentials of psychiatry. John Wiley \& Sons, Hoboken, New Jersey, USA. Pg no: 680.

6. Cheng SW, Hu WH, Hung DZ, Yang DY (2002) Anticholinergic poisoning from a large dose of Scopolia extract. Vet Hum Toxicol 44: 222-223.

7. O'Flynn K, O'Donohoe A, Gill M (1997) Gastrointestinal presentations of Munchausen's syndrome: three case reports. Irish Journal of Psychological Medicine 14: 153-155.

8. Mahapatra J, Quraishi SN, David A, Sampson S, Adams CE (2014) Flupenthixol decanoate (depot) for schizophrenia or other similar psychotic disorders. Cochrane Database Syst Rev 6: CD001470.

9. Ogino S, Miyamoto S, Miyake N, Yamaguchi N (2014) Benefits and limits of anticholinergic use in schizophrenia: focusing on its effect on cognitive function. Psychiatry Clin Neurosci 68: 37-49.

10. Lambert MT (1987) Paranoid psychoses after abuse of proprietary cold remedies. Br J Psychiatry 151: 548-550.

11. Dilsaver SC (1988) Antimuscarinic agents as substances of abuse: a review. J Clin Psychopharmacol 8: 14-22.

12. MORGENSTERN GF (1962) Trihexyphenidyl (Artane) intoxication due to overdosage with suicidal intent. Can Med Assoc J 87: 79-80.

13. Keehn JD (1972) Effects of trihexyphenidyl on schedule-induced alcohol drinking by rats. Psychonomic Science 29: 20-22.

14. HEYMANS C, HYDE JE, TERP P (1951) Action of trihexylphenidyl (artane) and atropine on central synaptic transmission. Arch Int Pharmacodyn Ther 86: $215-219$

15. Schneck HJ, Rupreht J (1989) Central Anticholinergic Syndrome (CAS) in anesthesia and intensive care. Acta Anaesthesiol Belg 40: 219-228.

16. Cohen S, Hunter CW, Yanni B, Striker P, Hijazi RH (2006) Central anticholinergic syndrome strikes again. J Clin Anesth 18: 399-400.

17. Drug Schedules Regulation to the Pharmacy Operations and Drug Scheduling Act of British Columbia (2012) College of Pharmacists of British Columbia, Vancouver, Canada.

18. Jordan Food and Drug Administration (JFDA) (1988) Narcotic Drugs and Psychotropic Substances Law. Jordan Food and Drug Administration, Jordan. 